\title{
Physician-adherence to pharmacotherapy guidelines for chronic heart failure in a tertiary health facility in Lagos, Nigeria
}

\author{
Janet N. Ajuluchukwu' ${ }^{1}$ Emmanuel N. Anyika², Kabiru A. Raji ${ }^{2}$ \\ 1. Department of Medicine, College of Medicine, University of Lagos, Lagos, Nigeria. 2. Department of Clinical Pharmacy \\ \& Biopharmacy, Faculty of Pharmacy, University of Lagos, Lagos, Nigeria.
}

Correspondence: Janet N. Ajuluchukwu. Address: Department of Medicine, College of Medicine, University of Lagos, Lagos, Nigeria. E-mail: ajulujay@usa.net

Received: August 11, 2013

Accepted: October 8, 2013

Online Published: October 30, 2013

DOI : $10.5430 /$ jha.v3n2p32

URL: http://dx.doi.org/10.5430/jha.v3n2p32

\section{Abstract}

Background: The increasing need for adherence evaluation of CHF amongst senior physicians in our environment prompted this study.

Objective: To determine physician-adherence to pharmacotherapy guidelines in CHF in an economically resource-poor tertiary health facility.

Methods: Review of prescription pattern of anti-CHF drug-class of 100 confirmed systolic-CHF patients was carried out. Data for adherence-evaluation were obtained from follow-up information from out-patient clinic-notes, while data on acute care medications and precipitating factors were from in-patient hospitalization notes.

Results: CHF patients aged $54.7 \pm 14.5$ years, had NYHA III/IV symptoms (47\%) and hypertension (61\%). Anti-CHF pharmacotherapy averaged three drug-types; and consisted of ACEI/ARB (83\%), $\beta$ blockers-BB (48\%), aldosterone antagonists (41\%), CG (82\%), and diuretics (75\%). Adherence was assessed as good or complete in 50\%, partial/ incomplete in $33 \%$; but non-adherent in $17 \%$ of the total. While overall physician-adherence was $59.6 \%$ on single drug-classes, survival- advantage combinations with ACEI/ARB+BB and ACEI/ARB+BB+AA were present in $40 \%$ and $16 \%$ respectively. Older patients ( $\geq 65$ years) had significantly lower prescriptions of all three classes of survival advantage anti-HF drugs, as follows: ACEI/ARB (56\% versus $95 \%)$; BB (37.5\% versus $52 \%)$; and AA (31\% versus $63 \%)$ $[p<.05]$.

Conclusion: BB and AA were under-prescribed. Physician-adherence to evidence-based anti-HF drug classes was variable and influenced by patient's age. It was also comparable with reports from other countries. Our physicians will benefit from a structured HF education and feed-back program.

\section{Key words}

Chronic heart failure, Systolic heart failure, Physician-adherence, Practice guidelines 


\section{I ntroduction}

Chronic heart failure (CHF) is a serious public health problem globally ${ }^{[1-3]}$ with a progressive and lethal course. There is clear evidence from land-mark studies of disease-modulating and survival-promoting pharmacological treatment using $\mathrm{ACEI}^{[4,5]}, \mathrm{ARB}^{[6]}, \mathrm{BB}^{[7]} \mathrm{AA}^{[8]}$, and hydralazine/isosorbide-dinitrate combinations ${ }^{[9]}$. However, the take-up of some or all trial findings may be slow or incomplete ${ }^{[10-12]}$. For bedside translation of trial findings, physicians should be aware and initiate treatment which includes such findings ${ }^{[10]}$. Thus, guidelines are developed and provided by several groups to help close such gaps, and simplify complex regimens ${ }^{[1,2,13]}$.

Undoubtedly, adherence to treatment guidelines influences CHF outcome positively ${ }^{[14,15]}$. Physician-adherence is one strategy to improve the dismal outcome in $\mathrm{CHF}^{[1,2,10-12,14,15]}$. Generally guidelines have been known to influence quality of care, and have been used as a performance measure for health facilities ${ }^{[12,16,17]}$. Globally, in recent times, multiple publications on physician-adherence to CHF guidelines attest to its growing importance ${ }^{[11,12,14,15,18-20]}$. Such studies have consistently uncovered variations and potential disparities in the care of heart failure patients ${ }^{[11,12,14,15,17-20]}$. Treatment of CHF is influenced by the patients' and physicians' gender with regard to evidence-based drugs and their dosage; with implications for gender-related treatment imbalance ${ }^{[24]}$.

Sub-optimal knowledge has been identified as a cause of poor adherence to evidence-based pharmacotherapy ${ }^{[10,11,18]}$. Even physicians' knowledge of guidelines does not in itself lead to better guideline implementation ${ }^{[25]}$. But, little is known of physician-adherence to CHF guidelines in real-life clinical scenario in Nigeria. Thus, the purpose of this study was to document prescriptions of pharmacotherapy for CHF in order to evaluate adherence to evidence-based CHF treatment guidelines in our tertiary facility.

\section{Materials and methods}

\subsection{Study location}

It was a University Teaching Hospital in Lagos, which is one of the two university-based tertiary health facilities in Lagos - Nigeria. The Lagos University Teaching Hospital is an academic/tertiary health facility affiliated to the University of Lagos, Lagos-Nigeria. This is a 700 bedded hospital, serving the Lagos State of Nigeria. This facility has wards for admission, as well as out-patients' clinic for out-patient and ambulatory follow up, with same physicians staffing both areas of care. Thus, previously admitted patients receive follow-up in the clinic, where necessary.

\subsection{Study design}

A retrospective study was carried out using case-notes of previously hospitalized adult patients with a diagnosis of CHF.

\subsection{Methods and materials}

\subsubsection{Aims and objectives}

- To evaluate physician adherence to evidence - based pharmacotherapy for chronic heart failure with reduced ejection fraction, using European Society of Cardiology (ESC) guidelines.

- To identify co-morbidities of HF and their prescribed treatment.

\subsubsection{Methods}

The Records Department of our Health facility identified all case-notes with a discharge code of heart failure. Clinical heart failure was based on the presence of two major Framingham criteria ${ }^{[21]}$. One of investigators (RKA-a post graduate/clinical pharmacist) studied these patients' records and selected the appropriate records based on the study 
inclusion and exclusion criteria. The inclusion criteria were: (a) heart failure admission during January 2010 - June 2011, (b) adult patients defined as age $>18$ years, (c) $\geq 2$ follow-up clinic visits, (d) evidence of impaired left ventricular function with ejection fraction $<35 \%{ }^{[1,2,3,21]}$, (e) data from clinic visit to include. (i) current NYHA class, (ii) heart rate $>50$ beats per minute, (iii) systolic blood pressure $>90 \mathrm{mmHg}$, (iv) serum creatinine $<220 \mu \mathrm{mol} / \mathrm{L}^{[12,15]}$. (f) anti-Heart Failure (HF) medication prescription ordered by senior registrar or consultant. Exclusion criteria were age $<18$ years, unavailable echocardiography results for classifying type of HF as reduced ejection fraction versus preserved ejection fraction HF, unavailable or missing data for blood pressure, heart rate, and serum creatinine.

Using above criteria, 160 case - notes were initially identified; however, 100 records were suitable for our study. The other 60 case-notes were excluded as follows: unavailable echocardiography results-20 records, preserved left ventricular function with $\mathrm{EF} \geq 35 \%$ - 34 records, missing clinical data, such as blood creatinine levels - six case-notes.

The data abstracted from case-notes and entered into our study proforma were age, sex, underlying heart disease, current NYHA, current medications for HFIn order to capture the burden of illness, we also included data of precipitating causes, and co-morbidities, and their treatment; which were identified during the hospital-admission phase.

Adherence indicators were based on the MAHLER study ${ }^{[15]}$, which defined adherence as proportion of patients whose physicians had prescribed evidence-based anti HF drug classes in the absence of contraindications. The evidence-based anti-HF classes are (a) ACEI/ ARB, (b) beta adrenergic blocker - BB, (c) aldosterone antagonist-AA, (d) cardiac glycoside-CG and (e) diuretic - DIUR ${ }^{[4-9]}$. However, the drug classes with survival-advantage are ACEI/ARB, BB and $\mathrm{AA}^{[4-9]}$. The flow-chart summary of ESC recommendations had suggested the following order for anti-HF drug classes: $\mathrm{ACEI} / \mathrm{ARB}$ as foundation drug-class, $+\mathrm{BB},+\mathrm{AA},+\mathrm{CG}$, with a comment that diuretic may be added if congestion was present ${ }^{[2]}$.

Adherence was assessed as good or complete, when the anti-HF classes commenced with ACEI/ARB, followed by BB and AA if required.

Adherence was assessed as "partial/incomplete" if "foundation" drug class was ACEI/ARB; but BB was omitted before AA or CG.

"Non-adherence" was defined as absence of "foundation" class of ACEI/ARB, or presence of other non-guideline medications for HF.

\subsection{Statistical analysis}

Data obtained were documented in a proforma designed for the study. The data were entered and analyzed using Epi-Info software version 3.51. Continuous parameters were recorded as means $\pm S D$. Descriptive data were given in percentages and proportions, while univariate comparison of proportion on specific medication class was also performed, based on age $<65$ years and $\geq 65$ years.

\section{Results}

The data from 100 CHF patients, consisting of 41 males and 59 females made up the reported sample. Table 1 shows the general characteristics. Clinical characteristics of patients showed that approximately half were still symptomatic with NYHA class 3/4 heart failure and elevated blood pressure was frequent. Use of ACEI/ARB and BB was noted in 83\% and $48 \%$ respectively. Co-morbidities and current medications are shown in Tables 2 and 3; showing that isolated hypertension reported in $45 \%$, and in combination with diabetes mellitus, was a predominant co-morbidity. In contrast, acute myocardial infarction from coronary artery heart disease was the least frequent co-morbidity. 
Table 1. Clinical characteristics of the study sample

\begin{tabular}{ll}
\hline Characteristic & Percentage (\%) \\
\hline Male:Female & $41: 59$ \\
Average age (years) & $54.7 \pm 14.5$ \\
Age $\geq 65$ years (\%) & 32 \\
SBP $\geq 140 \mathrm{mmHg}(\%)$ & 43 \\
DBP $\geq 90 \mathrm{mmHg}(\%)$ & 44 \\
NYHA III/IV (\%) & 47 \\
Ejection Fraction (\%) & $33.2 \pm 1.0$ \\
ACEI/ARB use (\%) & 83 \\
Beta Blocker use (\%) & 48 \\
\hline
\end{tabular}

Note. $\mathrm{SBP}=$ Systolic blood pressure; $\mathrm{DBP}=$ diastolic blood pressure; $\mathrm{NYHA}=$ New York Heart Association; ACEI/ARB = angiotensin converting enzyme inhibitor/angiotensin receptor blocker.

Table 2. Distribution of co-morbid conditions in CHF

\begin{tabular}{ll}
\hline Co-morbid condition to CHF & Percentage (\%) \\
\hline Hypertension & 45 \\
Hypertension and diabetes & 16 \\
Idiopathic Dilated cardiomyopathy & 27 \\
Dyslipidemia & 20 \\
Thyrotoxicosis & 6 \\
Rheumatic valve disease & 6 \\
Atrial fibrillation & 6 \\
Myocardial infarction & 3 \\
\hline
\end{tabular}

Table 3. Combinations of anti-heart failure drugs used in stable CHF

\begin{tabular}{ll}
\hline Drug Combinations & $\mathbf{\%}$ \\
\hline ACEI/ARB-diuretic & 10 \\
ACEI/ARB-CG-AA & 10 \\
ACEI/ARB-BB-CG-AA & 16 \\
ACEI/ARB-DIUR-CG & 23 \\
ACEI/ARB-DIUR-CG-+BB & 24 \\
OTHERS (non ACEI/ARB based) & 17 \\
\hline
\end{tabular}

Note. $\mathrm{ACEI} / \mathrm{ARB}=$ angiotensin converting enzyme inhibitor/angiotensin receptor blocker; $\mathrm{CG}=$ cardiac glycoside; $\mathrm{BB}=$ beta blocker; $\mathrm{AA}=$ aldosterone antagonist/blocker; DIUR $=$ diuretic.

Amongst the HF patients, the five anti-CHF drug classes were prescribed in different proportions. Patients' records show that the following drug classes were prescribed as follows: ACEI/ARB; BB; AA; diuretics; and CG were prescribed in $83 \%, 48 \%, 41 \%, 75 \%$, and $82 \%$ respectively. Thus the overall physician adherence was $59.6 \%$ for the five anti-CHF drug classes. Table 3 shows drug combinations of anti-CHF classes. No individual patient's record showed a prescription of one single HF drug or class, thus all patients received anti-HF drug prescriptions as combinations. Two-thirds (66.2\%) of patients received different combinations of $\mathrm{ACEI} / \mathrm{ARB}+\mathrm{BB}$. Adherence evaluation was classed as complete, partial and non-adherent to practice guidelines in $50 \%, 33 \%$ and $17 \%$ of the clinical records. Thus, non-rational combinations were noted in $17 \%$ of total sample, where CG (digoxin) and AA were used without ACEI/ARB. All prescriptions contained an average of $3.3 \mathrm{CHF}$ medications, while $40 \%$ of prescriptions had $\geq 4$ medications. Table 4 shows that age influenced prescription of survival anti-CHF medications. Significantly higher proportion of patients $\leq 65$ years received all three classes of survival-advantage HF medications, than those older than 65 years. Tables 5 and 6 are summarized data 
pertaining to the acute hospitalization phase. Results show that the commonest precipitating causes of heart failure were infections (27\%), drug and diet non-compliance (27\%) and electrolyte imbalance (30\%). Patterns of drug use during the acute hospital phase are shown in Table 6, which concerned acute treatment of heart failure, the treatment of co-morbidities and correction of the precipitating factors.

Table 4. Effect of age on adherence on survival-advantage anti-CHF drug classes

\begin{tabular}{lll}
\hline Drug class & $<\mathbf{6 5}$ years $\mathbf{n}=\mathbf{6 8}(\%)$ & $\geq \mathbf{6 5}$ years $\mathbf{n}=\mathbf{3 2}(\%)$ \\
\hline ACEI/ARB & $65(95)$ & $18(56.0)$ \\
BB & $36(52)$ & $12(37.5)$ \\
AA & $43(63.2)$ & $10(31.3)$ \\
\hline
\end{tabular}

Note. $P<.05 ; \mathrm{ACEI} / \mathrm{ARB}=$ angiotensin converting enzyme inhibitor/angiotension receptor blocker; $\mathrm{BB}=$ beta blocker; $\mathrm{AA}=$ aldosterone antagonist/blocker.

Table 5. CHF reversible precipitating causes during hospitalization

\begin{tabular}{ll}
\hline Precipitants & Percentage (\%) \\
\hline Hypokalemia & 30 \\
Infections & 27 \\
Severe hypertension & 18 \\
Herbal concoctions/alcohol & 17 \\
Arrhythmia & 17 \\
Dietary and drug non-adherence & 17 \\
Pulmonary embolism & 6 \\
Acute myocardial infarction & 3 \\
\hline
\end{tabular}

Table 6. Non-CHF medications and/or drug class used during acute phase of heart failure admission

\begin{tabular}{ll}
\hline Medications/drug class/agents & Percentage (\%) \\
\hline Aspirin & 57 \\
Anti-infective & 27 \\
Lipid lowering & 24 \\
Warfarin & 21 \\
Antihypertensive & 18 \\
Hypoglycemic & 16 \\
Antiarrhythmic & 14 \\
Heparin/enoxaparin & 40 \\
Non-steroidal anti-inflammatory & 8 \\
Anti-ulcer & 3 \\
Inotropic (Dopamine/Dobutamine) & 10 \\
Potassium supplements & 7 \\
\hline
\end{tabular}

\section{Discussion}

CHF guidelines have been provided by several authorities to aid adherence for patients and physicians in this complex therapeutic scenario ${ }^{[1,2,13]}$. The last decade has witnessed keen interest in CHF physician-adherence, resulting in several publications from Europe ${ }^{[15]}$, USA ${ }^{[12,17,23]}$, Japan ${ }^{[14]}$, Pakistan ${ }^{[18]}$, Australia ${ }^{[19]}$ and South Africa ${ }^{[20]}$. These international studies have highlighted several differences in degree of adherence, and perceived barriers to adherence ${ }^{[17]}$. Some methodological issues were also uncovered as the USA adherence indicators ${ }^{[12,17,23]}$ were based only on the use of 
ACEI/ARB and beta blockers; while the European MAHLER survey assessed the five drug classes of anti-CHF therapy ${ }^{[15]}$.

Real life physician-adherence studies are scanty in Africa; although few patient-adherence studies are now available ${ }^{[11,20]}$. Our data demonstrated a fair overall adherence of $59.6 \%$ to the five anti-CHF therapy; which is similar to global adherence indicator of $60 \%$ in Europe ${ }^{[15]}$. Evidence shows ACEI as the "foundation" of pharmacological treatment for systolic CHF, and of proven benefit in all classes of heart failure ${ }^{[1,2,4,5]}$. Thus, with regard to specific classes, the present study demonstrated a good physician - adherence of $83 \%$ for ACEI/ARB, which is comparable to those of South Africa, Europe and USA ${ }^{[12,15,17,20]}$. Interestingly, ours was higher than the ACEI/ARB adherence noted in Japan ${ }^{[14]}$, and rural Australia ${ }^{[19]}$. Other authors have suggested that class of physicians or seniority of physicians may influence level of knowledge and adherence ${ }^{[14-16]}$.

About half of our patients were in class III/IV NYHA, indicating severe symptoms, even as out-patients. With our reported good adherence to ACEI/ARB, such patients would be eligible for additional BB and AA therapy ${ }^{[1,2,7,8]}$, although our data uncovered serious under-prescription of BB and AA classes. Consistently, wide variations in adherence have been reported for beta adrenergic blockers in CHF in other studies ${ }^{[12,15,17-20]}$. In our study, adherence to BB (48\%) was surprisingly higher than $34 \%$ reported for rural Australia, but much lower than $57.8 \%$ in Japan ${ }^{[14]}$ and $84 \%$ for both $\mathrm{USA}^{[12]}$, and South Africa ${ }^{[20]}$. Reluctance to prescribe certain drug classes, such as beta blocker in CHF has been blamed on presence of multiple co-morbidities ${ }^{[10]}$, fear of drug interactions ${ }^{[18,20]}$, presence of contra-indications ${ }^{[15]}$, and cost/health economics ${ }^{[18,25]}$. Thus, limited knowledge of guidelines ${ }^{[1,18]}$ and physician-perceived potential for adverse effects may contribute to the present low level of prescription of BB class. In other studies, reasons for BB underprescription included concerns regarding co-morbidities, presence of asthma and other polypharmacy ${ }^{[19,20]}$. However, with the exclusion of case-notes with contraindications in this present study, the expectation was a higher adherence rate.

As previously noted in the HART and MAHLER studies, adherence was defined as the prescription of a recommended drug class in the chart or case-notes ${ }^{[12,17]}$. However, unlike those studies, our results further pointed out that the mere presence of a drug in the prescription or chart does not translate to guideline-adherence; since drug combinations may be partially or completely inappropriate. In addition to adherence, some studies examined drug target doses ${ }^{[15,19]}$ but did not assess the appropriateness of the anti-CHF combinations. In the absence of contra-indications, we noted complete non-adherence or inappropriate combinations in approximately one-fifth of our patients. This was demonstrated by spironolactone (aldactone-antagonist) and digoxin prescription without initial "foundation” class of ACEI/ARB.

The clinical profile of the patients reviewed in our study showed that the aspects of average age, aetiology of heart failure and co-morbidities were consistent with other African studies ${ }^{[3,11,20,22]}$; but differ greatly from patients in industrialized world ${ }^{[12,14,17,19]}$. While the present study highlights the predominance of hypertension and diabetes as important co-morbidities, the major aetiological factor of CHF in the West is related to coronary artery disease ${ }^{[1,2,12,14,15]}$. The high prevalence of hypertension in our study is however consistent with reports from similar clinical settings ${ }^{[3,20,22,28]}{ }^{\text {. The }}$ high adherence to ACEI/ARB class in this study is not unexpected, as the chief co-morbidities of CHF were hypertension and diabetes - conditions with proven benefit from the use of these drug classes ${ }^{[1,2]}$. In addition, our methodology ensured that selected patient-notes were those without contraindication.

Our patients had a high co-morbidity burden. In the hospital phase, reversible precipitants of decompensation were common, such as infections, severe hypertension and electrolyte imbalance. In addition, chronic co-morbidities of hypertension, diabetes, atrial fibrillation and dyslipidemia were frequent; some patients having more than one co-morbid condition. These co-morbidities have implications for the number of different drug classes, finances/cost, complexity of regimen, and also increase in the potential for adverse drug interaction ${ }^{[18,19]}$. These factors have been implicated in previous patient- and physician non-adherence reports ${ }^{[10,12,15]}$. Interestingly, the MAHLER study ${ }^{[15]}$ also identified 
co-morbidities of hypertension, diabetes, atrial fibrillation as predictors of poor outcome - measured as "time to cardiovascular event".

Overall, prescription of diuretics was frequent, but that of aldosterone antagonist was low at $<50 \%$. This finding may be a reflection of our type of patients, as African patients are known for late presentation and more readily present with gross peripheral edema ${ }^{[3,11,20,22]}$. The high prescription of diuretics may indicate an over - prescription or non - adherence. The evidence-based guideline recommendation for aldosterone antagonist (AA) use ${ }^{[1,2,8]}$, is for advanced CHF: defined as persistence of symptoms, despite standard HF therapy with a combination of ACEI, BB, and diuretics ${ }^{[8]}$. In the present study, spironolactone (an AA), was appropriately added-on to standard treatment in only $26 \%$ of the cohort; and its prescription was not evidence-based, in the remainder. Several investigators had previously stated that AA prescription might be limited by actual presence or fear of hyperkalemia; and this risk would be higher, when AA is added-on to ACEI/ARB - two potassium sparing agents ${ }^{[4,5,8]}$. Although the use of diuretics is "routine" for acute and chronic heart failure ${ }^{[1,2]}$, some recent reports are questioning the quality of evidence; and "raising eyebrows" at the outcome of especially high-dose diuretics in heart failure ${ }^{[23]}$. Our current data also showed that age influenced all classes of survival anti-CHF drug class. Other studies also noted this and suggested that older age may be associated with higher numbers of co-morbidities and higher potential for adverse effects ${ }^{[12,14,19]}$. The obvious absence of the isosorbide dinitratehydralazine combination in any of our prescriptions requires mention. This combination demonstrated significant efficacy and survival advantage in African Americans in the A-HEFT study ${ }^{[9]}$; and so was recommended for patients of African descent ${ }^{[1]}$. Reasons for ignoring this beneficial combination in our practice needs further study.

Association between common over-the-counter (OTC) medications, including non-steroidal anti inflammatory drugs (NSAIDS) and exacerbation of heart failure should be made known to patients and health care providers, to avoid detrimental adverse drug-drug and drug-disease interactions that could result in hospitalization ${ }^{[26]}$. Pharmacists can assist in the evidence-based selection of drug therapy by making every therapeutic decision with diligence, to avoid potentials for long-term morbidity and mortality ${ }^{[27,28]}$, and improving guideline compliance in patients with heart failure ${ }^{[29]}$. The findings of a survey among pharmacists suggest that higher involvement of pharmacists in post-discharge patients, would yield improvement in adherence issues ${ }^{[30]}$.

\section{Strengths and limitations}

This study evaluated certain class of senior physicians, as previous studies suggested that variation in adherence may be due to a factor of physician experience ${ }^{[11,18]}$. We examined the prescription patterns of experienced health-care providers (senior registrars and consultants). This therefore eliminates the potential effect of age and seniority of prescribers ${ }^{[15]}$. The MAHLER study had previously proposed the concept of "positive" and "negative" adherence ${ }^{[15]}$ and our current interest was on positive adherence ${ }^{[12,15]}$. Our methodology ensured appropriate selection of such charts. We adopted a chart review, which is a method of evaluating real-life practice ${ }^{[17,18]}$. Our patients had previous admission in our facility for CHF; which provided additional opportunity to examine certain admission issues. Patients included were more than thirty days post-discharge, which would have ensured stability of symptoms, and allowed time for including drug classes and up-titration of doses. Our study is a retrospective survey in the apex health care facility in Lagos - Nigeria, with referrals from other levels of health-care, as well as private hospitals. The findings may not be generalized to other levels of the health care community. However, the performance at this level is relevant and requires study, for audit and practice evaluation ${ }^{[16,17]}$.

Limitations: As with other retrospective studies, our study limitations would include incomplete clinical data required to ascertain compliance. However, this limitation was minimized by excluding such records. Although, this introduced another confounding factor, relating to fewer patient records and generalisability. Another limitation may be the use of an European guideline for an African health facility. This situation is considered acceptable as HF is a global menace and is a final common pathway of various cardiac diseases ${ }^{[1,2]}$, with comparable prognosis globally. An African generated 
evidence-based guideline is not yet available. Need to "customize" the ESC guidelines is debatable, as similar studies from around the world: Japan ${ }^{[14]}$, Pakistan ${ }^{[18]}$, Australia ${ }^{[19]}$, South Africa ${ }^{[20]}$ used guidelines without any customization.

Clinical Implications: Our data uncovered both outright non-adherence to guidelines and under-prescription of survival advantage classes of BB and AA. Such non-adherent combination was noted in nearly $20 \%$ of our HF patients, where digoxin was combined with spironolactone (AA), in the absence of prior ACEI/ARB treatment. No guideline has recommended this combination ${ }^{[1,2,8]}$; and one can only guess at the clinicians' thoughts and objectives. Nevertheless, other non-HF indications for our common AA-spironolactone exist, such its potassium-sparing diuretic effect or need in secondary aldosteronism ${ }^{[1,8]}$.

Future direction should include prospective studies on the reason for non-adherence, in addition to the provision of an evidence-based Nigerian guideline with a flow-chart summary. Based on previous recommendations ${ }^{[10,16,17]}$, research should be directed to physician's self-evaluation, and external evaluation using standard performance measures. On-going education on best practices in HF care should include strategies, such as clinical reminders and feed-back.

\section{Conclusion}

Physician-adherence to evidence-based guidelines for pharmacotherapy for CHF showed variation: being good for certain drug classes and poor for others. The degree of adherence was comparable to similar settings in Africa and other continents. However, it was unacceptably low for BB and AA, and older age was associated with lower adherence.

\section{Abbreviations/ Key}

ACEI - angiotensin converting enzyme inhibitors; ARB - angiotensin receptor blocker; BB - $\beta$-blocker; AA - aldosterone antagonist; CG - cardiac glycoside; DIUR - diuretic; CHF- chronic heart failure; NYHA - New York Heart Association.

\section{Competing interests}

The authors declare that they have no competing interests.

\section{Acknowledgements and funding}

We would like to acknowledge Dr. Mbakwem AC for her useful comments. We are also grateful to the staff of Records Department of the institution for availing the case-notes for data collection during the period. The research was funded by the authors.

\section{References}

[1] Hunt SA, Abraham WT, Chin MH, et al. 2009 focused update incorporated into ACC/AHA 2005 Guidelines for the diagnosis and management of heart failure in the adults: a report of American College of Cardiology Foundation / American Heart Association Taskforce on practice guidelines: developed in collaboration with International Society of Heart and Lung transplantation. Circulation. 2009; 119: e391-e479. PMid: 19324966. http://dx.doi.org/10.1161/CIRCULATIONAHA.109.192065

[2] McMurray JJV, Adamopoulos S, Anker S D, Auricchio A, Bohm M, Dickstein K, et al. The Task Force for Diagnosis and Treatment of Acute and Chronic Heart Failure 2012 of the European Society of Cardiology. Eur Heart J. doi: 10.1093/eurheartj/ehs 104: 1-61.

[3] Adebayo KA, Adebiyi AA, Oladapo OO, Ogah OS, Aje A, Ojji DB, et al. Characterisation of heart failure with normal ejection fraction in a tertiary hospital in Nigeria. BMC Cardiovasc Dis. 2009; 9: 52. http://dx.doi.org/10.1186/1471-2261-9-52

[4] Klein L, O'Connor CM, Gattis WA, et al. Pharmacologic therapy for patients with chronic heart failure and reduced systolic function: review of trials and practical considerations. Am J Cardiol. 2003; 91 (9A): 18F-40F.

http://dx.doi.org/10.1016/S0002-9149(02)03336-2 
[5] Braunwald E, Bristow MR. Chronic heart failure: fifty years of progress. Circulation. 2000; 102; IV14-IV23. PMid: 11080127. http://dx.doi.org/10.1161/01.CIR.102.suppl_4.IV-14

[6] Cohn JN, Tognoni G. for the Valsartan Heart Failure Trial Investigators. A randomized trial of the angiotensin receptor blocker valsartan in chronic heart failure. New Engl J Med. 2001; 345: 1667-1675. PMid: 11759645. http://dx.doi.org/10.1056/NEJMoa010713

[7] Packer M, Coates AJ. Fowler MB, Katus HA, Krum H, et al. for the Carvedilol Prospective Randomised Cumulative Survival Study Group. Effects of carvedilol on survival in severe chronic heart failure. New Engl J Med. 2001; 344: 1651-58. PMid: 11386263. http://dx.doi.org/10.1056/NEJM200105313442201

[8] Pitt B, Zannand F, Remme WJ, Cody R, Castaigne A, et al. for the Randomised Aldactone Evaluation Study group. The effects of spironolactone on mortality in patients with severe heart failure. New Engl J Med. 1999; 341: 709-711. PMid: 10471456. http://dx.doi.org/10.1056/NEJM199909023411001

[9] Taylor A for AHEFT investigators. Combination of isosorbide and hydralazine in Blacks with heart failure. N Engl J Med. 2004; 351: 2049-2057. PMid: 15533851. http://dx.doi.org/10.1056/NEJMoa042934

[10] Phillips LS, Branch WT, Cook CB, Doyle JP, Gallina DL, Miller CD, et al. Clinical Inertia. Ann Intern Med. 2001 ; $135: 825-834$. PMid: 11694107. http://dx.doi.org/10.7326/0003-4819-135-9-200111060-00012

[11] Mbakwem AC, Ajuluchukwu JNA. Perception of Nigerian Internal Medicine residents on the diagnosis and management of heart failure. Nig Postgrad Med J. 2007; 14: 336-340. PMid: 18163145.

[12] Calvin JE, Shanbarg S, Avery E, Kane J, Richardson D, Powell L. Adherence to evidence-based guidelines for heart failure in physicians and their patients: lessons from the heart failure adherence retention trial (HART). Congestive Heart Fail. 2012; 18: 72-78. http://dx.doi.org/10.1111/j.1751-7133.2011.00263.x

[13] Abdu-Aguye I. for Expert Committee Members. Standard treatment guidelines of heart failure. Federal Ministry of Health Nigeria, in collaboration with WHO, EC, DFID. 2008; Chapter 3: 25-32.

[14] Ohsaka T, Inomata T, Naruke T, Koitabashi T, Nishii M, Takauchi I, et al. Clinical impact of guidelines on outcomes in CHF in Japan. Int Heart J. 2008; 48: 57-73.

[15] Komajda M, Lapuerta N, Gonzalez-Juanatey JR, van Veldhuisen DJ, Erdmann E, Tavazzi L, et al. Adherence to guidelines is a predictor of outcome in CHF: the MAHLER Survey. Eur Heart J. 2005; 26: 1653-59. PMid: 15827061. http://dx.doi.org/10.1093/eurheartj/ehi251

[16] Milchak JL, Carter BL, Ardery G, James PA. Measuring adherence to practice guidelines for management of hypertension: an evaluation of the literature. Hypertension. 2004; 44: 602-08. PMid: 15381676. http://dx.doi.org/10.1161/01.HYP.0000144100.29945.5e

[17] Kahn LS, Fox CH, Olawaiye A, Servos TJ, Mclean-Plunkett E. Facilitating quality improvement in physician management of co-morbid chronic disease in an urban minority practice. J Natl Med Assoc. 2007; 99: 377-383. PMid: 17444426.

[18] Shoukat S, Gowani SA, Tagni AM, Hassan RUI, Bhutta ZA, Malik AI, et al. Adherence to ESC Guidelines for CHF - a national survey of cardiologists in Pakistan. BMC Cardiovasc Dis. 2011; 11: 68-73. PMid: 22093082. http://dx.doi.org/10.1186/1471-2261-11-68

[19] Yao D, Wang L, Curran S, Ball P. Adherence to treatment guidelines in the pharmacological management of congestive heart failure in an Australia population. J Geriat Cardiol. 2011; 8: 88-92. PMid: 22783291. http://dx.doi.org/10.3724/SP.J.1263.2011.00088

[20] Ruf V, Stewart S, Pretorius S, Kubheka M, Lautenshlager Christine PP, et al. Medication adherence, self care behavior, and knowledge on heart failure in urban South Africans: Heart of Soweto Studies. Cardiovasc J Afr. 2010; 21: 86-92. PMid: 20532432.

[21] Vasan RS, Benjamin EJ, Larson MG, Leip EP, Wang TJ, Wilson PWF, et al. Plasma natriuretic peptides for community screening for left ventricular hypertrophy and systolic function. The Framingham Study. JAMA. 2002; 288: 1252-59. PMid: 12215132. http://dx.doi.org/10.1001/jama.288.10.1252

[22] Ajuluchukwu JN, Ekure EN, Mbakwem AC, Okoromah CN, Oladipo OO. Reliability and accuracy of point-of-care amino-terminal probrain natriuretic peptide in congestive heart failure patients. Internet J Cardiol. 2011; 9: 1-10.

[23] Yilmaz MB, Gavat E, Salem R, Lassis J, Mkola M, Larbi S, et al. Impact of diuretic dosing on mortality in acute heart failure, using a propensity-matched analysis. Eur J Heart Fail. 2011; 13: 1244-52. PMid: 22024466. http://dx.doi.org/10.1093/eurjhf/hfr121

[24] Baumhäkel M, Müller U, Böhm M. Influence of gender of physicians and patients on guideline recommended treatment of chronic heart failure in a cross-sectional study. Eur. J. Heart Failure. 2009; 11(3): 299-303. doi:10.1093/1093/eurjhf041.// Available from: www.ncbi.nih.gov/pubmed/19158153 (23 October, 2012, date last accessed).

[25] Karbach U, Schubert I, Hagemeister J, Ernstmann N, Pfaff H, Höpp HW. Physicians' knowledge of and compliance with guidelines. An exploratory study in cardiovascular disease. Deutsches Arzteblatt International. 2011; 108(5): 61-9. doi:10.3238/arzebl.2011.0061. 
[26] Thomason AR, Platt DJ, Stubbs HE. A pharmacists guide to systolic heart failure. US Pharm. 2006; 7: 58-68. Available from www.uspharmacist.com/content/feature/c/11603/

[27] Bayram M, De Luca L, Massie MB, Gheorghiade M. Reassessment of dobutamine, dopamine and milrinone in the management of acute heart failure syndromes. American J Cardiol. 2005; 96: 47G-58G. PMid: 16181823. http://dx.doi.org/10.1016/j.amjcard.2005.07.021

[28] Nordeen JD, Smith AJ. Pharrmacists' role in acute decompensated heart failure management. US Pharm. 2010; 35(2): HS8-19.

[29] Ziman ME, Bui HT, Smith CS, Tsukiji LA, Asmatey VM, Chu SB, et al. The Pharmacists' role in improving guideline compliance for thyroid function testing in patients with heart failure. J Pharm Pract. 2012; 25(2): 195-200. PMid: 21844214. http://dx.doi.org/10.1177/0897190011416008

[30] Anyika EN, Alade TB. Evaluation of pharmacists' participation in post-admission ward rounds in a tertiary hospital in South-West, Nigeria. Nig Qt J. Hosp. Med. 2009; 19: 151- 54. PMid: 20836320. 